\title{
FOUCAULT: UMA INTRODUÇÃO *
}

\author{
Salma Tannus Muchail **
}

TRANS/FORM/AÇĀO/27

MUCHAIL, S. T. - Foucault: uma introdução. Trans/Form/Ação, São Paulo, $3: 127-40,1980$.

RESUMO: O texto nasceu de uma comunicação apresentada e discutida junto a um público de psicólogos (em agosto de 1977) e cujo objetivo era preparar (ou despertar) os ouvintes para a eventual leitura direta dos escritos de Michel Foucault, particularmente aqueles escritos que interessassem mais de perto a estudiosos da área de psicologia. Para tanto, escolheu_se pois, elaborar uma "introdução" à leitura do livro Histoire de la folie à l'âge classique, introdução esta que é, feita através de duas vias de abordagem: a primeira, mais específica, detém.se no exame de um momento preciso do livro, a saber, a "Introdução" da 2.a Parte; a segunda, mais genérica, busca "localizar" o livro no itinerário dos escritos de M. Foucault (até a época de L'Archéologie du savoir), fornece uma visão ampla de seu conteúdo interno e se conclui com uma remissão ao Prefácio de Les Mots et les Choses onde se coloca a questão da diferenciação entre o "outro" e o "mesmo".

UNITERMOS: razão e desrazão; discurso, gesto, conhecimento e reconhecimento; o "outro" e o "mesmo".

\section{Observações preliminares}

Ao título que foi estabelecido para esta exposição ("Foucault") permitimonos acrescentar um sub-título ("Uma introdução"). Primeiramente, por que não apenas "Foucault"? Porque a simples expressão é um nome próprio e faz pensar na pessoa quando, coerentemente com o método foucaultiano, não nos ateremos aqui ao homem, mas aos seus escritos. Vale a pena lembrar a sua já tão divulgada afirmação: "que importa quem fala; alguém disse: "que importe quem fala" " ( 7 , p. 81). Uma afirmação com dois segmen- tos. O primeiro ("que importa quem fala") refere-se ao sujeito de qualquer discurso; o segundo porém, na medida mesma em que a afirmação é do próprio sujeito Foucault, constitutiva pois do seu discurso, a ele mesmo se refere: "alguém disse: 'que importa quem fala' ". Não se trata pois de responder à pergunta "quem é Foucault?" - para a qual já temos a resposta: "alguém". Interessa-nos, isto sim, os seus escritos, escritos que trazem a data e a marca da cultura ocidenta! européia do século XX. Em segundo lugar, por que "uma introdução"? Porque não pretendemos, nem podemos, em

* Palestra pronunciada por ocasiấo de uma Semana de Debates do curso de Psicologia da PUC — São Paulo, em agosto de 1977.

** Professora associada do Depto. de Filosofia da PUC — São Paulo. 
MUCHAIL, S.T. - Foucault: uma introdução. Trans/Form/Ação, São Paulo, 3: 127-40, 1980.

algumas poucas horas discorrer sobre toda a riqueza dos muitos escritos de Michel Foucault. Extremamente atuais e em vias de constituição, numerosos e sobretudo geradores de grandes polêmicas, eles exigem um cuidado de investigação que consumiria anos de análise por parte de um especialista. E, é preciso esclarecer, não somos especialista nos escritos de Foucault. Tão somente nos iniciamos no seu estudo, razão pela qual só podemos expor um pouco do pouco que conhecemos: "uma introdução", portanto.

Contudo, no caso presente, mesmo "uma introdução" levan'ta pelo menos duas ordens de problemas: primeiro, é uma proposta arriscada e por isto exige uma advertência; segundo, é uma empresa ousada e por isto exige uma delimitação. Senão, vejamos.

E uma proposta arriscada e exige uma advertência. Solicitado a redigir um prefácio para uma nova edição de Histoire de la folie, o próprio Foucault, em o fazendo, manifesta certa reticência, já que um prefácio poderia representar uma espécie de imposição prévia, pelo autor, de um tipo de leitura ou de uma interpretação regidas pela sua soberana autoridade. "Isto não seria conforme - escreve ele - principalmente ao que deve ser, em relação a um livro, a reserva de quem o escreveu" (4, p. 7). E logo a seguir: "Quereria que um livro, pelo menos do lado daquele que o escreveu nada mais fosse que as frases de que é feito; que ele não se desdobre neste primeiro simulacro de si mesmo que é um prefácio e que pretende fornecer a lei a todos aqueles que no futuro poderão ser formados a partir dele" (4, p. 8). E quando no final, o próprio Foucault levanta a si mesmo a objeção: "- Mas vós acabais de fazer um prefácio", responde ironicamente: "- Pelo menos ele é curto" (4, p. 9). Ora, uma introdução é mais ou menos como um prefácio ou um prólogo. $\mathrm{E}$, se "do lado daquele que o escreveu" há reservas quanto a redigir um prefácio dirigido ao leitor, do lado do leitor há um risco em pretender elaborar uma introdução endereçada a ouvintes. Daí a necessária advertência: assim como o prefácio não se substitui ao livro, às "frases de que é feito", que esta introdução não se substitua à leitura direta dos escritos de Foucault, mas tão somente, acorde talvez no ouvinte, o desejo de ir até eles.

E uma empresa ousada e exige uma delimitação. Já aludimos à riqueza de conteúdo dos escritos de Foucault. Uma introdução a eles, se adjetivada "geral" poderia simplesmente empobrecê-los senão deformá-los. Daí a necessidade de uma demarcação de limites no interior mesmo de uma pretendida introdução. Com efeito, aquela riqueza de conteúdo permite, de fato, uma diversidade muito grande de enfoques, entre os quais é mister optar. Antes de uma explicitação da escolha de limites que estabelecemos para a presente introdução, não será inútil apontar alguns dentre outros enfoques possíveis de "introduzir" aos escritos de Foucault já que, embora os tenhamos excluído, sua indicação significa pelo menos a abertura de pistas para investigações posteriores. Enumeramos pois, algumas delas:

a) — Uma "introdução" poderia ser feita à maneira de um apanhado amplo das obras principais de Foucault, recompondo o itinerário por elas percorrido e cercando os elementos básicos do seu conteúdo. Enfoque descartado sobretudo porque seria de algum modo repetir - certamente com menor destreza e 
MUCHAIL, S.T. - Foucault: uma introdução. Trans/Form/Ação, São Paulo, 3: 127-40, 1980.

maior incompletude - o que vários estudiosos já fizeram*.

b) - Uma "introdução" poderia enfatizar o método de Foucault enquanto historiador, isto é, sua tão questionada "arqueologia". Este enfoque - que aliás tem gerado a grande maioria das polêmicas - é descartado na medida em que não somente exigiria uma abordagem minuciosa do que poderíamos talvez chamar uma "teoria da História" inclusa no livro L'Archéologie du savoir, como ainda levantaria questões cujo interesse estaria próximo menos de um público de psicólogos que de historiadores.

c) - Uma "introdução" poderia compor-se na forma de exame de um assunto importante e básico dos escritos de Foucault. Seria o caso, por exemplo, de um estudo das condições de possibilidade do surgimento bem como do anúncio da morte do homem como objeto de conhecimento, isto é, uma investigação das condições de possibilidade de emergência e de eventual desaparecimento das chamadas "ciências humanas". Este enfoque é descartado na medida em que requereria um percurso tão completo quanto possível do livro Les mots et les choses, já que só no seu capítulo final desemboca explicitamente o referido assunto.

d) - Uma "introdução" poderia ainda ser elaborada a partir de assuntos paralelos, complementares ou consequentes àqueles diretamente tratados por Foucault. Por exemplo, uma investigação a propósito do posicionamento digamos assim, "político" que ocupariam seus escritos. Enfoque também descartado, primeiro porque algo parecido já foi realizado $(* *)$; segundo, porque semelhante trabalho, para ser efetuado com suficiente competência e honestidade intelectual suporia não apenas um exaustivo conhecimento como mais ainda, um conhecimento bastante amadurecido de todos os livros e artigos de e sobre Foucault.

Excluídos estes enfoques, mas abertos a título de pistas, indiquemos a opção que demarca os limites e o itinerário do presente estudo. Escolhemos fronteiras modestas, estabelecendo duas vias sucessivas de abordagem que de certo modo se justapõem apenas ou talvez se complementem. Ambas pretendem se reportar a assuntos que, de algum modo, interessem mais de perto a ouvintes da área de psicologia. A primeira via de abordagem, um pouco mais específica, será algo assim como uma "amostragem" onde retomaremos um momento determinado do livro Histoire de la folie à l'âge classique, mais precisamente, um exame da "Introdução" da Segunda Parte. Na segunda via, mais genérica e com que concluiremos, teceremos algumas considerações de caráter mais amplo sobre o mesmo livro em que se situa aquele momento tratado na primeira abordagem.

2. Uma amostragem específica (sobre a "Introdução" da 2a. Parte de Histoire de la folie à l'âge classique)

\subsection{Primeiras considerações}

Organizando em 3 Partes, Histoire de la folie à l'âge classique é um livro que

* Veja-se, por ex., o artigo de S.P. Rouanet, "A Gramática do Homicídio" em (8), p. 91-138; o capítulo "O não-estruturalismo de Michel Foucault" de Auzias em (2), p. 88-100; o cap. Michel Foucault, franco-atirador", de Lepargneur em(9), p. 75-88; os artigos, principalmente os de Canguilhem, de Burgelin, de Revault d'Allones e de Amiot, reunidos em (1).

Esprit.

* Veja-se (7), onde Foucault responde às questões propostas pela equipe da revista 
MUCHAIL, S.T. - Foucault: uma introdu ção. Trans/Form/Ação, São Paulo, 3: 127-40, 1980.

reserva lugares para duas "Introduções", uma precedendo a $2 .^{\text {a }}$ Parte, outra precedendo a 3? Parte. Escolhemos a "Introdução" da $2^{\text {a }}$ Parte para uma visão mais detida, na medida em que ali encontramos elementos teóricos mais amplos que, além de interessantes para a compreensão do livro como um todo, podem de algum modo, ser dele destacados sem grandes riscos de fragmentação e sem o prejuízo de mutilá-lo. A retomada deste trecho que buscaremos apenas compreender e fazer compreender será uma "amostragem", visando, repitamo-lo, não mais que despertar o interesse pela leitura do próprio livro.

Esta "Introdução" se inicia com algumas observações a propósito do "objeto" loucura, observações que aliás, teremos ocasião de retomar na última parte da nossa exposicão. Dentro do espaço de nossa cultura ocidental, a loucura, de cuja história trata o livro, não é um "objeto" preciso, uno, homogêneo, contínuo, definido, de sentido único e direção linear. Pelo contrário, a loucura e a consciência que dela se tem aparecem numa multiplicidade de experiências, numa dispersão de ordens, numa divergência de direções, numa desigualdade de sentidos. E o que nos anuncia o primeiro parágrafo: "a consciência da loucura, ao menos na cultura européia, jamais foi um fato maciço, formando um bloco e se metamorforseando como um conjunto homogêneo. Para a consciência ocidental, a loucura surge simultaneamente em pontos múltiplos, formando uma constelação que pouco a pouco se desloca, transforma seu desenho e cuja figura reserva talvez o enigma de uma verdade. Sentido sempre fracassado" (4, p. 181).

Poder-se-ia objetar porém que a consciência de qualquer objeto, em se tratando sobretudo de qualquer região do saber, de algum modo não possui contor- nos precisos, continuidade regular, completude unificada. Com efeito, a verdade só aparece através de "perfis" (4, p. 181). Não há nenhuma forma de conhecimento que se apresente com uma única figura, surgida de uma vez por todas, sem dispersões e sem incoerências. Todavia, se a dispersão, a multiplicidade, caracteriza, de algum modo, toda forma de saber, no caso preciso da loucura esta característica com que se agudiza à maneira de algo que lhe é essencial, que lhe é fundamenio. "E enquanto na maior parte das outras formas do saber - escreve Foucault - a convergência se esboça através de cała perfil, aqui a divergência estaria inscrita nas estruturas, só permitindo uma consciência da loucura já quebrada, fragmentada desde o princípio em um debate que não pode se encerrar (4, p. 181). A experiência de percepção da loucura não é pois nem serena nem una, faz-se sempre num debate. De modo tal que não há uma maneira única de se ter "consciência" da loucura, mas várias, e todas elas têm estado presentes - simultâneamente, mesmo quando há prioridade de uma sobre outras - na história ocidental de nossa sensibilidade à loucura . Estas formas múltiplas de consciência da loucura são esquematizadas por Foucault em quatro tipos: "consciência crítica", "consciência prática", "consciência enunciátiva", "consciência analítica" (4, p. 182-185). Faremos, com ele, a descrição separada de cada uma, para depois examinarmos sua autonomia e sua mútua solidariedade. A seguir, veremos a presença destas quatro formas no devir histórico. Finalmente, qual a experiência fundamental da loucura durante a Idade Clássica.

\subsection{Descrição das formas de cons- ciência da loucura}

a) - "Consciência crítica" - Poderia também ser denominada "consciên- 
MUCHAIL, S.T. - Foucault: uma introdução. Trans/Form/Ação, São Paulo, 3: 127-40, 1980.

cia dialética" (4, p. 187) ou se quisermos, talvez consciência denunciativa ou irônica. Aqui, a loucura é experimentada através de seu confronto opositivo com a razão; delimita-se a loucura pela diferença entre loucura e razão. Contudo, esta experiência não é simples; inclui um debate porque a oposição é ambígua e é também um conflito; e é um conflito por ser reversivel (daí, ser esta consciência "dialética"). De certo modo, é como se, embora saibamos que há diferença entre razão e loucura, nada nos garante, nenhum referencial nos determina, nenhum "ponto fixo" (4, p. 182) nos assegura de que lado está a razão e de que lado está a loucura. É a "lucidez irônica" (4, p. 183) da consciência crítica. Uma ilustração deste conflito da reversibilidade nascida da ausência de um parâmetro é fornecida por Foucault nos versos de um poeta: "aqueles que para viajar embarcam sobre as águas, vêem passar a terra, não a embarcação" (*). Ou nos seguintes: "tanto mais me burilo e me aperfeiçoo, tanto mais creio que todo mundo desvaria" (**). Esta forma de consciência é engajada " $n a$ diferença e homogeneidade da loucura com a razão $(4$, p. 183).

b) - "Consciência prática" Poderia também ser denominada "cisão ritual" $(4$, p. 187), ou se quisermos, talvez consciência normativa ou social. Aqui, a loucura é experimentada como uma realidade imposta pelas normas de um grupo social. A oposição agora se estabelece entre o "dentro" e o "fora" do grupo, dependentemente dos padrões e valores, não diretamente da razão, mas do grupo, que este pretende ditar as normas da ra- zão. Percebemos como esta consciência é baseada não mais "na diferença e homogeneidade da loucura com a razão", mas sim " $n a$ diferença entre loucura e razão, consciência tornada possível na homogeneidade do grupo considerado como portador das normas da razão" (4, p. 183). Mas esta experiência também comporta uma ambiguiidade: afinal, quem determina as normas que regem o "dentro" e o "fora" é apenas o "dentro" do grupo. Experiência de certo modo "serena", mas fundamentalmente intranqüila, já que sua serenidade requer a cesura, a separação daqueles considerados contra a ordem estabelecida. Se na primeira forma de consciência a loucura é ameaça à razão, nesta agora é ameaça à ordem. E para serenar a ameaça não há propriamente um "combate", mas um "rito", um gesto, a cerimônia da cisão que enclausura a loucura para reduzí-la ao silêncio $(* * *)$.

c) - "Consciência enunciativa" Poderia também ser denominada "recorhecimento lírico" (4, p. 187), ou se quisermos, talvez consciência indicativa ou constatativa. Aqui, a loucura é experimentada antes de qualquer juízo ou diagnóstico, antes de qualquer nível de valores (racionais ou grupais); ela é reconhecida como um ser que está aí e que é de imediato constatado, quase que apontado com um gesto, na existência concreta do louco. Contudo, esta simples percepção também não é tranqüila. Supõe, de algum modo, um recuo em relação à lcucura, uma certa dominação sobre ela, já que só se a reconhece se houver certo reconhecimento anterior da não-loucura. Citando Blake, ilustra Foucault: "é por-

(*) Cf. Régnier, Satire XIV. Oeuvres complètes, ed. Railaud, v. 9; apud (4), p. 182.

(*) Cf. Régnier, op. cit., v 7-8; apud (4), p. 183. Sugerimos que o filme "|Este mundo é dos loucos" seria tambẻm uma ilustração para esta forma de consciência da loucura...

$(*)$ Sugerimos que o filme "Um estranho no ninho" seria aqui uma ilustração. 
MUCHAIL, S.T. - Foucault: uma introdução. Trans/Form/Ação, São Paulo, 3: 127-40, 1980.

que os outros foram loucos que nós podemos não sê-lo" (*).

d) - "Consciência analítica" - Poderia também ser denominada "saber" da loucura $(4$, p. 187), ou se quisermos, talvez consciência reflexiva ou cognitiva. E a consciência da loucura nas "suas formas", "seus fenômenos", seus "modos de aparição" (4, p. 185). Aqui se busca perceber a loucura no que nela é cognoscível, reduzindo-a ao que nela é inteligível, sem o "perigo", sem a "cisão", sem o "recuo" inclusos nas formas anteriores. E a forma de consciência que "funda a possibilidade de um saber objetivo da loucura" (4, p. 185). Como veremos mais adiante, esta forma, cada vez mais "racionalizada", tem prioridade na Idade Moderna. Contudo, vale lembrar que mesmo reduzida à uma objetivação intelegível e racional, a loucura guarda ainda seu fundo "patético", seu "dramático", que escapa à "objetividade" do cognoscível. E, como lembra Foucault, em páginas anteriores do livro, este elemento irredutível ao racional, este "fascínio do trágico", subsiste mesmo na obscuridade, como que "nas noites dos pensamentos e dos sonhos" $(4$, p. 391$)$, e será sempre não só pressentido como ainda, de tempos em tempos, testemunhado (evoquemos Goya, Sade, Nietzsche, Van Gogh... (**)

Realizada a análise separada de cada uma das quatro formas de consciência da loucura, Foucault faz ver que nenhuma é isolada, mas, solidárias entre si apoiamse, justificam-se, referem-se mutuamente. Dois exemplos o revelam. Primeiro, todo conhecimento da loucura, por mais objetivo e científico (4⿳亠口冋 forma), supõe sempre um "movimento anterior de um debate crítico (1a. forma) onde a razão é medida com a loucura, experimentando-a ao mesmo tempo na simples oposição e no perigo da imediata reversibilidade; supõe também como virtualidade sempre presente no seu horizonte, uma cisão prática (2a. forma) em que o grupo confirma e reforça seus valores pela conjuração da loucura $(4$, p. 185$)(* * *)$. Por outro lado, toda "consciência crítica" (1 1 a forma) tende a apaziguar seu debate numa "consciência analítica" ( $4 \stackrel{\text { a }}{\text { forma}) . ~}$

No entanto, solidárias, estas quatro formas guardam, cada qual sua autonomia, seus traços particulares. A primeira ("consciência crítica") abarca "uma região da linguagem" onde se confrontam os opostos (por ex., "sentido e não-sentido", verdade e erro"). A segunda ("consciência prática") abarca a região silenciosa, não dita, mas prática, dos ritos, do gesto separador. A terceira ("consciência enunciativa") abarca a região do reconhecimento. A quarta ("consciência analítica") abarca a região do conhecimento.

\subsection{As formas de consciência da lou- cura no devir históríco}

No curso da história, a consciência da loucura aparece sob as quatro formas. Ocorre porém que, sem a anulação de uma ou outra, há períodos de privilégio ou de prioridade de uma sobre outras, ou há movimentos em que algumas destas formas se agrupam. Deste devir histórico,

(*) Cf. Blake, Le Mariage du ciel et de l'enfer, trad. A. Gide, p. 24; apud (4), p. 185. Sugerimos que a canção "Balada para um louco", interpretada por Amelita Baltar seria aqui uma "lírica" ilustração...

(**) Sugerimos como ilustração desta forma de consciência, o filme "Vida em Família", sobretudo no seu final, quando a loucura é objeto de uma "aula acadêmica".

(**) Os parênteses são nossos. 
MUCHAIL, S.T. - Foucault: uma introdução. Trans/Form/Ação, São Paulo, 3: 127-40, 1980.

Foucault traça, nesta "Introdução", um esboço em três momentos: Renascimento, Idade Clássica e Idade Moderna, tratando do segundo deles em último lugar, já que é ele que constitui o núcleo central do livro. Esquematizando: o Renascimento (por volta dos séculos XV a XVII) caracterizou-se sobretudo pelo privilégio da "consciência crítica" ou "dialética" da loưcura (1a. forma); a Idade Moderna (por volta dos séculos XIX e XX) tem se caracterizado sobretudo por um privilégio da "consciência analítica" ou "cognitiva" (4a. forma); entre estes dois momentos, a Idade Clássica (por volta dos séculos XVII e XVIII), com sua característica peculiar. Com efeito, neste período dá-se um curioso "agrupamento" das quatro formas de consciência da loucura como que em duas metades, em dois domínios ou em duas regiões. Num grupo, a "consciência crítica" e a "consciência prática" (1a. e 2a. formas); no outro, a "consciência enunciativa" e a "consciência analítica" (3a. e 4a. formas). A primeira região se manifesta numa forma institucionalizada que é o internamento. Com efeito, a prática do internamento agrupa, por um lado, a oposição entre razão e loucura, oposição reversível e por isto perigosa (1a. forma) e, por outro, o gesto prático que exige o afastamento, a reclusão de tudo o que pode significar aquele perigo (2a. forma); é a redução da loucura à sua forma "negạtiva", ao silêncio da exclusão. A segunda região (reunindo as formas reconhecedora e conhecedora de consciência da loucura) é a busca da verdade da loucura que se manifesta fenomenalmente, tentando "dizer sua verdade" $(4$, p. 188$)$, como "modo de presença positiva no mundo" $(4$, p. 188$)$. No primeiro grupo, "as formas dramáticas da cisão", e no segundo, "o ciclo do conhecimento" (4, p. 191).
Poder-se-ia obietar talvez que em qualquer época há sempre uma certa separação ou "inadequação" entre, por um lado, "práticas de exclusão e de proteção", e por outro, "a experiência mais teórica" (4, p. 189). Contudo, Foucault realça que semelhante "inadequacão" é sempre geradora de algum mal-estar e consequentemente de um desejo de superação em direção a uma unidade almejada. Ora, o que caracteriza a Idade Clássica é que precisamente, durante este período, aquela "inadequação" entre as duas metades não é acompanhada "nem mesmo de mal-estar nem de aspiração a uma unidade" (4, p. 189). E é em razão disto que este período se presta a uma análise bastante rica da sensibilidade à loucura. A impossibilidade de diálogo, de confronto, entre o gesto (1a. região) e o discurso (2a. região) determinava uma espécie de "calmaria", de apaziguamento de cada região em si mesma, fornecendo à experiência da Idade Clássica "a aparência do sono" (4, p. 190), cuja análise, precisamente, o livro Histoire de la folie se destina a empreender. Ora, este empreendimento revela que aquela separação em duas metades ou regiōes tem uma razão de ser numa experiência considerada fundamental.

\subsection{A experiência fundamental da loucura na Idade Clássica.}

Cindidas, as duas regiões da experiência da loucura durante a Idade Clássica, apresentam uma espécie de fundo comum. Estruturalmente, há entre elas uma espécie de correlação, uma espécie de suporte uno tanto para as formas práticas que culminam no internamento quanto para as formas conceituais, uma certa correspondência entre o "evento" e o desenvolvimento conceitual" (4, p. 190). Esta correspondência porém, não se resume numa espécie de relação me- 
MUCHAIL, S.T. - Foucault: uma introdução. Trans/Form/Ação, São Paulo, 3: 127-40, 1980.

cânica entre prática, de um lado, e teoria de outro, ou mesmo, se quisermos, entre uma infra e uma supra-estrutura. Com efeito, a forma conceitual não se reduz a mera "expressão" da forma prática, como se as formações discursivas fossem simples "reflexo" das formas sociais. Pelo contrário, ambas as regiões são simultaneamente "teóricas" e "práticas". A primeira região (que agrupa as duas primeiras formas de consciência da loucura, envolvendo o gesto da reclusão pelo internamento) "é necessariamente misturada a uma certa concepção política, jurídica, econômica, do indivíduo na sociedade" $\left(4\right.$, p. $\left.191^{*}\right)$; e a segunda (que agrupa as duas últimas formas de consciência da loucura, envolvendo a consciência médica e científica) "é sempre virtualmente comprometida num sistema de operações que deveria apagar os sintomas ou dominar as causas" (4, p 191. O grifo é nosso). Ora, se a cisão entre os dois agrupamentos não se baseia na separação pura e simples entre teoria e prática, o que a funda e torna possível, a unidade que autoriza ambos os momentos é algo assim como uma certä experiência de base, única, "que sustenta, explica e justifica a prática do internamento e o ciclo do conhecimento" (4, p. 191). Esta experiência fundamental da loucura na Idade Clássica é a experiência da desrazão, fundo subjacente que, como que "por baixo" da cisão entre as duas regiões, "estende sua secreta coerência" $(4$ p. 191). E a experiência da desrazão a razão de ser tanto da cisão quanto da coerência entre os dois domínios. E esta experiência se explica pelos valores da cultura da época, nela instaurando sua contradição. Com efeito, os valores culturais da Idade Clássica eram sobremaneira "investidos na razão" (4, p. 192). Não é a Idade Clássica afinal, a famosa "idade da razão", o ponto forte do "cogito" cartesiano? Ora, por isto mesmo a Idade Clássica também investiu na loucura e só pôde fazê-lo na forma de desrazão. E na desrazão investiu "o máximo" e o "mínimo". O "máximo", enquanto a desrazão, sendo a contradição imediata da razão, por contraste opositivo justificava a própria valorização da razão; o "mínimo", porque sendo o polo contrário da razão, o sem valor, era apenas a razão precedida de um índice negativo, uma razão que se desvanece; o "outro", de que falaremos mais adiante.

Eis, em resumo, uma amostragem de um momento de um dos livros de $\mathbf{M}$. Foucault. Complementando esta amostragem, e ampliando os horizontes de nossa "Introdução", passemos a algumas considerações menos específicas, onde poderemos "situar" melhor o livro como um todo, dentro do conjunto das obras de M. Foucault.

3. Uma visão mais ampla (sobre Histoire de la folie à l'âge classique)

\section{1. "Localização" do livro}

Numa "Entrevista com Michel Foucault", um dos entrevistadores enuncia uma afirmação acatada por Foucault, a respeito do conjunto de seus principais escritos até a época de l'Archéologie du savoir, a saber, que este conjunto se articula basicamente em dois momentos: "um momento empírico-descritivo" e "um momento de reflexão metodológica" $(8$, p. 17$)$. Em outro artigo, o mesmo entrevistador repete que "o percurso intelectual de Foucault é composto de dois momenos", sendo o primeiro "da descrição empírica de de-

(*) O grifo é nosso. 
MUCHAIL, S.T. - Foucault: uma introdu ção. Trans/Form/Ação, São Paulo, 3: 127-40, 1980.

terminados segmentos históricos" e o segundo, "da reflexão crítica $(8$, p. 93). E explica: "Na primeira fase, Foucault descreve, sucessivamente, o discurso da loucura, o discurso da medicina, o discurso das epistemes. Na segunda, os princípios teóricos postos em prática intuitivamente nestes trabalhos empíricos são isolados e codificados. E o momento da Arqueologia" $(8$, p. 93). Assim, no primeiro momento, localizamos três obras principais: Histoire de la folie, Naissance de la clinique e Les Mots et les choses. No segundo, L'Archéologie du savoir (É preciso lembrar que após esta fase, Foucault vem publicando outras obras que podemos qualificar de caráter empíricodescritivo, onde pretende pôr sistematicamente em prática os princípios estabelecidos em L'Archéologie du Savoir; trata-se, sobretudo de Surveiller et punir e Histoire de la sexualitê). Assim, "localizada" no primeiro momento, Histoire de la folie é "o primeiro grande esforço descritivo de Foucault" (8, p. 93). Detendo-nos no primeiro momento $-\mathrm{e}$, de acordo ainda com o artigo de Rouanet que vimos utilizando - é possível estabelecer certa distinção interna que reparte as três obras principais como que em dois sub-momentos. As duas primeiras (Histoire de la folie e Naissance de la clinique) constituem o primeiro sub-momento, a que Rouanet chama "fase transitiva" $(8$, p. 107) e a última (Les mots $e$ les choses) pertence ao segundo submomento, denominável fase "intransitiva" (8, p. 109). A "fase transitiva" caracteriza-se pelo fato de que a análise dos discursos (o da loucura e o da medicina) é relacionada com práticas extra-discursivas (práticas sociais, econômicas, instituições, etc.), ao passo que a "fase intransitiva" atém-se ao plano estrito da descrição dos discursos. Para ilustrar, escutemos o pró- prio Foucault: "Não se pode dizer que o discurso psicopatológico europeu até Freud tenha suportado um nível de cientificidade muito elaborado. Em compensação, todos os contextos institucionais, sociais e econômicos desse discurso eram importantes. E evidente que a maneira de internar os loucos de diagnosticá-los, de medicá-los, de excluí-los da sociedade ou incluí-los num local de internamento, era tributária de estruturas sociais, de condições econômicas, tais como o desemprego, as necessidades de mão-de-obra, $\mathrm{e}^{\dagger} \mathrm{c}$. No fundo, era um pouco tudo isto que tinha me seduzido no tema" $(8, \mathrm{p}$. 20-21).

Localizando o livro no conjunto dos escritos de Foucault, reportemo-nos agora ao seu interior, ou seja, a uma espécie de "localização", também ampla, do seu conteúdo.

\section{2. "Localização" do conteúdo}

Se é "um pouco de tudo isto" que teria seduzido Foucault em direção ao estudo da loucura isto não significa porém que ao pesquisar "a loucura", partisse ele de uma espécie de tema "dado" como que de antemão, de um "objeto" de sentido já definido e constituído, buscando então simplesmente "reconstituir" sua trajetória histórica. Na verdade, não há como captar "previamente" o que vem a ser "o ser mesmo da loucura", "seu conteúdo secreto" ( 3, p. 45$)$, para, em seguida investigar o que se disse sobre ela no decurso do tempo. Pelo contrário - coisa a que já tivemos ocasião de aludir - a loucura não aparece como um "objeto" nem uno nem preciso; surge, em contrapartida, através de enuncia- 
MUCHAIL, S.T. - Foucault: uma introdu ção. Trans/Form/Ação, São Paulo, 3: 127-40, 1980.

dos e experiências as mais variáveis. Por exemplo, o "objeto" loucura, tal como é colocado "pelos enunciados médicos dos séculos XVII e XVIII não é idêntico ao objeto que se desenha através das sentenças jurídicas ou das medidas policiais" ( 3 , p. 45-46). Assim, escreve ainda Foucault, "o que constituía problema era a emer. gência de todo um conjunto de objetos bastante entrecruzados e complexos" (3, p. 86)*. Todavia, assim como não se tratava de escrever a história de um "objeto" definido ( $a$ loucura), também não se tratava de descrever uma "disciplina" instituída (a psiquiatria) e recompor sua "história". A este respeito, escutemos ainda Foucault "Ora, interrogando esta disciplina nova, descobrimos duas coisas: o que a tornou possível na época em que apareceu, o que determinou esta grande mudança na economia dos conceitos, das análises e das demonstrações, foi tudo um jogo de relações entre a hospitalização, o internamento, as condições e os procedimentos da exclusão social, as regras da jurisprudência, as normas do trabalho industrial e da moral burguesa, em suma, todo um conjunto que, para esta prática discursiva, caracteriza-se a formação de seus enunciados; mas esta prática não se manifesta apenas numa düsciplina de estatuto e pretensão científica; encontramola igualmente em exercício nos textos jurídicos, nas expressões literárias, nas reflexões filosóficas, nas decisões de ordem política, nos propósitos cotidianos, nas opiniões (...). Mas há mais: ascendendo no tempo e buscando o que pôde preceder, nos séculos XVII e XVIII a instauração da psiquiatria, percebemos que não havia nenhuma disciplina prévia: o que era dito das manias, dos delírios, das melancolias, das doenças nervosas, pelos médicos da época clássica, de modo algum constituia uma disciplina autônoma (...). Entretanto, malgrado a ausência de qualquer disciplina instituida, uma prática discursiva se exercia, com regularidade e sua consistência. Certamente, esta prática discursiva era investida na medicina, mas também o era nos regulamentos administrativos, nos textos literários ou filosóficos, na casuística, nas teorias ou nos projetos de trabalho obrigatório ou de assistência aos pobres. Na época clássica, temos pois uma formação discursiva e uma positividade perfeitamente acessíveis à descrição, às quais não corresponde nenhuma disciplina definida que se pudesse comparar à psiquiatria $(3, \mathrm{p} .233-234) * *$. Assim, Histoire de la folie nem é a história de um objeto estabelecido num só sentido, nem de uma disciplina cuja gênese é perscrutada. Visto o que não é a Histoire de la folie, ouçamos outra passagem de Foucault onde, agora de modo positivo, indica claramente que o sistema por ele analisado em Histoire de la folie "define antes o referencial, a gama enunciativa, a rede teórica, os pontos de escolha que tornaram possível em sua dispersão mesma os enunciados médicos, as regras institucionais, as medidas administrativas, os textos jurídicos, as expressões literárias, as formulações filosóficas. A formação discursiva, constituída e descrita pela análise, - continua ele - extravasa largamente o que se poderia contar como sendo a pré-história da psicopatologia ou como a gênese de seus conceitos" (6, p. 40). Nem história de "um objeto", nem história de "uma disciplina", mas sim, história daquilo que tornou possível a loucura como objeto de saber. Como afirma Rouanet, a Histoire de la folle é

(*) O grifo é nosso. Em se tratando de formações discursivas, Rouanet chega a usar a expressão "caleidoscópio de objetos" (Cf. (8), p. 103).

(**) Os grifos são nossos. 
MUCHAIL, S.T. - Foucault: uma introdução. Trans/Form/Ação, São Paulo, 3: 127-40, 1980.

antes a história "das atitudes em relação à loucura. Mais importante que o discurso psiquiátrico - continua - é o gesto que instaura a loucura, e a torna pensável para o conhecimento. O saber da loucura é derivado em relação ao gesto original de partilha, à cesura que cinde o mundo da razão e o mundo da desrazão. A história da loucura não é portanto a história desse saber, mas da sensibilidade à loucura no espaço Ocidental" $(8$, p. 93$) *$.

Para prosseguir e completar nossa explanação, deter-nos-emos um pouco justamente nos dois segmentos desta expressão final: "sensibilidade à loucura" e, em seguida, "no espaço Ocidental". O exame do segundo segmento constituirá o último item do nosso estudo. Vejamos antes, a "sensibilidade à loucura". Retomando ainda Rouanet, diremos que esta "sensibilidade à loucura", cuja história é traçada, percorre três fases, a saber, "a indiferenciação, a segregação, o asilo" ( 8 , p. 93). A primeira fase caracteriza o período renascentista (por volta dos séculos XV a XVII); a segunda, o período clássico (por volta dos séculos XVII e XVIII); a terceira, o período moderno (por volta dos séculos XIX e XX). Vários estudos foram publicados, que reportam sinteticamente o conteúdo destas três fases, assim bem como das fases percorridas em Naissance de la Clinique e em Les mots et les choses. Abster-nosemos pois, de repetir esta tarefa, mesmo porque ou correríamos o risco da incompletude, ou pelo contrário, o de excessivas minúcias que não caberiam num momento de nosso estudo precisamente subintitulado "uma visão mais ampla"...

Resta-nos ver o segundo segmento daquela expressão, a saber, "sensibilidade à loucura no espaço Ocidental". Dele se ocupará nosso último item.

\subsection{O "outro" e o "mesmo"}

"No espaço Ocidental" quer dizer não mais que: "em nosso espaço", no espaço da nossa cultura. Mas esta simples referência pode conduzir a questões bas. tante sérias e interessantes. Para explorá-la, remetemo-nos ao Prefácio de Les mots et les choses, onde Foucault faz explicitamente uma distinção entre o "outro" e o "mesmo", e cuja retomada permitir-nos a não só a ocasião de um breve confronto entre Les mots et les choses e Histoire de la folie, como ainda e principalmente, nos ajudará a cerrar melhor, num último aspecto, nossa tentativa de uma "localização" mais larga de Histoire de la folie.

O "outro" pode ser captado em dois sentidos: num sentido mais amplo e num sentido mais estrito.

$\mathrm{Na}$ acepção mais ampla, podemos entender o "outro" como o limite de pensamento para uma cultura, isto é, aquilo que para uma determinada cultura lhe é estranho, no sentido de não lhe ser possível "nomear, falar, pensar" (5, p. 11). Uma ilustração deste "limite" dá início às primeiras páginas do referido Prefácio. Trata-se da retomada de uma classificação dos animais, citada, segundo Foucault, por Jorge Luiz Borges, a partir de uma enciclopédia chinesa. Ouçamo-la. Ela diz que "os animais se dividem em: a) pertencentes ao imperador, b) embalsamados, c) domesticados, d) leitões, e) sereias, f) fabulosos, g) cães em liberdade, $\mathrm{h}$ ) incluídos na presente classificação, i) que se agitam como loucos, j) inumeráveis, k) desenhados com um pincel muito fino de pêlo de camelo, l) e etecetera, m) que acabam de quebrar a

\footnotetext{
(*) Os grifos são nossos.
} 
MUCHAIL, S.T'. - Foucault: uma introdução. Trans/Form/Ação, São Paulo, 3: 127-40, 1980.

bilha, n) que de longe parecem moscas" $(5$, p. 7$)$. Sem dúvida, esta classificação reúne, para nós, de modo incongruente, categorias sem coerência. Três termos nos serão aqui úteis para fundamentar nossas considerações: ordem, lugar, espaço. Com efeito, naquela classificação, uma única ordem parece vincular a sequiência de classes ali reunidas, a saber, a da nossa série alfabética, é justamente esta ordem que ali nos parece descabida e impensável. Assim, o absurdo da ordem parece se dever à sua ausência de lugar, isto é, à ausência de um lugar comum para as classes enumeradas, lugar que fosse justamente capaz de justificar sua reunião e sua ordenação ainda que meramente alfabética. "O absurdo arruína o $e$ (ordem) da enumeração, marcando de impossibilidade o em (lugar) onde se repartem as coisas enumeradas" $(5, \mathrm{p}$. 9) *. Todavia, lugar e ordem dependem de um espaço suficientemente homogêneo para que dentro dele ou sobre ele, possam ser as coisas localizáveis e ordenáveis. $\mathbf{O}$ absurdo se funda finalmente, nesta estranha justaposição do $e$ (ordem), do em (lugar), do sobre (espaço), (5, p. 8). Ora, o espaço que torna as coisas localizáveis e ordenáveis, é o mesmo que as torna pensáveis, nomeáveis, dizíveis. E o "espaço de acolhimento", diz Foucault (5, p. 9) sem o qual não é possível "nomear, falar, pensar". "Atopia, afasia" (5, p. 10).

Contudo, semelhante classificação dos animais que nos vem servindo de ilustração, se impensável, inominável, indizível o é para nós, não porém, digamos assim, em si mesma. Com efeito, ela parece pensável, nomeável, dizível, no espaço de outra cultura, estranha à nossa, limite da nossa. Não é simplesmente ausente de espaço; apenas repousa sobre outro espaço (Afinal, lembra ironicamente Foucault, "em nosso sonho, a China não é justamente o lugar privilegiado do espaço?" (5, p. 10). "Haveria assim escreve ele - na outra extremidade da terra que habitamos, uma cultura voltada inteiramente à ordenação da extensão, mas que não distribuiria a proliferação dos seres em nenhum dos espaços onde nos é possível nomear, falar, pensar" (5, p. 11).

Em suma, no sentido mais amplo, o "outro" é aquilo que nos limita e nos escapa por nos ser não só estranho como ainda exterior, "fora" dos quadros espaciais de nossa cultura. A referência a este sentido é feita a fim de indicar que em Les mots et les choses não será questão do "outro", mas do "mesmo", já que o livro buscará precisamente detectar o espaço, o solo, dentro ou sobre o qual nos tem sido possível, a nós, "nomear, falar, pensar".

Entretanto, podemos entender o "outro" num sentido mas estrito: é o estranho, não porém exterior. Ao contrário, do interior mesmo da nossa cultura, pertencendo ao seu espaço, é a diferença que a limita por dentro, o "não permitido" interno, a sua "exceção" (4, p. 199). Também neste sentido, Les mots et les choses não é uma história do "outro", mas do "mesmo", uma história onde se interroga a maneira como nossa cultura "experimenta a proximidade das coisas, com ela estabelece o quadro de seus parentescos e a ordem segundo a qual se deve percorrê-los" (5, p. 15). Porém, a Histoire de la folie, a história da "sensibilidade à loucura no espaço Ocidental" é precisamente uma história do "outro", isto é, da loucura como elemento interior

( ${ }^{*}$ Os parênteses são nossos. 
MUCHAIL, S.T. - Foucault: uma introdução. Trans/Form/Ação, São Paulo, 3: 127-40, 1980.

à nossa cultura, mas "estranho" a ela, sua diferença, seu limite interno; pensável pois, nomeável pois, dizível pois, mas para ser submetida aos critérios do "permissível", do "mesmo". "A história da loucura - escreve Foucault - seria a história do outro - daquilo que, para uma cultura é ao mesmo tempo interior e estrangeiro, devendo portanto ser $e x$ cluído (para conjugar o perigo interior que constitui) mas em a encerrando (para reduzir-lhe a alteridade)" (5, p. 15) *. Inclusa, porém reclusa.

E esta história (que muito provavelmente seria talvez aplicável, de algum modo, à história individual de cada um de nós), a do Outro - diferença e exceção, presença incômoda, mas presença que se busca compreender na leitura de Histoire de la folie.

Concluamos assim, com aquela mesma advertência a que aludimos no início de nossa explanação: que ela não se substitua à leitura direta dos escritos de Foucault, mas muito ao contrário, estimule a vontade de uma investigação cuidada e rigorosa; e finalmente, que esta advertência seja agora menos que uma advertência, uma sugestão; mais que uma sugestão, um convite.

TRANS/FORM/AÇãO/27

MUCHAIL, S. T. - Foucault: an introduction. Trans/Form/Ação, São Paulo, 3 :12740, 1980.

SUMMARY: This text comes from a communication presented to and discussed with an audience of psychologists (in August 1977). Its aim was to prepare (or to awaken) the hearers to a possible direct reading of Michel Foucault's writings, especially those more closely related to the area of psychology. With this view in mind a choice was made to elaborate an "introduction" to the reading of Histoire de la folie à l'âge classique, this introduction being done by way of two approaches: the first one, more specific, is restricted to the survey of a precise stretch of the book, the "Introduction" to the Second Part; the other one, more general, intends to "locate" the book on the sequence of M. Foucault's writings (until L'Archeologie du savoir), provides a comprehensive view of its internal content and concludes with a reference to the Preface of Les Mots et les Choses, where it is raised the question of the differentiation between the "other" and the "same".

UNITERMS: Reason and unreason; discourse; gesture; knowledge and recognition; the "other" and the "same".

\section{REFERÊNCIAS BIBLIOGRĀFICAS}

1. ANALISIS de Michel Foucault. Trad. esp. de B. Stolier. Buenos Aires, Tiempo Contemporáneo, 1970. (Biblioteca de Ciências Sociais, Colleción Signos).
2. AUZIAS, J. M. Chaves do estruturalismo. Trad. de N. O. Caixeiro. Rio de Janeiro, Civ. Brasileira, 1972. (Chaves da Cultura Atual, 2).

(*) Os grifos são nossos. 
MUCHAIL, S.T. - Foucault: uma introdução. Trans/Form/Ação, São Paulo, 3: 127-40, 1980.

3. FOUCAULT, M. L'archeologie $d u$ savoir. Paris, Gallimard, $1969 . \quad$ (Bibliothèque des Sciences Humaines).

4. FOUCAULT, M. Histoire de la folie à l'âge classique. Nouvelle êd. Paris, Gallimard, 1972. (Bibliothèque des Histoires).

5. FOUCAULT, M. Les mots et les choses: une archéologie des sciences humaines. Paris, Gallimard, 1966. (Bibliothèque des Sciences Humaines).

6. FOUCAULT, M. Resposta ao círculo de epistemologia. In: Estruturalismo $e$ teoria da linguagem. Trad. de L.F. Baeta Neves. Petrópolis, Vozes, 1971. p. 12-52.
7. FOUCAULT, M. Resposta a uma questão: a epistemologia. Tempo bras., 28: 57-81, jan./mar., 1972.

8. FOUCAULT, M. O homem e o discurso: a arqueologia de Michel Foucault. Rio de Janeiro, Tempo Brasileiro, 1971. (Comunicação, 3). Cf. "Entrevista com Michel Foucault" por S.P. Rouanet e J.G. Merquior, p. 17-42; Rouanet, S.P., "A gramática do homicídio", p. 91-139.

9. LEPARGNEUR, H. Introdução aos estruturalismos. São Paulo, Herder/ EDUSP, 1972. 